\title{
Prevalence and contributing factors of birth asphyxia among the neonates delivered at Nigist Eleni Mohammed memorial teaching hospital, Southern Ethiopia: a cross- sectional study
}

\author{
Ritbano Ahmed Abdo * (D), Hassen Mosa Halil, Biruk Assefa Kebede, Abebe Alemu Anshebo and
} Negeso Gebeyehu Gejo

\begin{abstract}
Background: Birth asphyxia is a major contributor to neonatal mortality worldwide. In Ethiopia, birth asphyxia remains a severe condition that leads to significant mortality and morbidity. This study aims to assess the prevalence and contributing factors of birth asphyxia among the neonates delivered at the Nigist Eleni Mohammed Memorial Teaching Hospital, Southern Ethiopia.

Methods: This hospital-based cross-sectional study was carried out on 279 participants using the systematic sampling method during June 1-30, 2019. Data were collected using a pretested structured interviewer administered questionnaire, check list and chart review, which was used to retrieve medical information and mother's test results that could not be captured by the interview. Data were entered into EpiData (version 3.1) and analyzed using SPSS software (version 24). Multivariable regression analysis was used to identify the association between the independent variables and outcome variable with a 95\% confidence interval (CI).

Result: The overall prevalence of birth asphyxia among newborns was found to be $15.1 \%$. Factors that were significantly associated with birth asphyxia included mothers aged $\geq 35$ ( $A O R=6.4 ; 95 \% \mathrm{Cl}=2.0-20.5$ ), primigravida $(A O R=5.1 ; 95 \% \mathrm{Cl}=2.0-13.3)$, prolonged second stage of labor $(\mathrm{AOR}=4.6 ; 95 \% \mathrm{Cl}=1.6-13.3)$, preterm birth $(\mathrm{AOR}=$ 4.7; $95 \% \mathrm{Cl}=1.5-14.1)$, meconium stained amniotic fluid ( $\mathrm{AOR}=7.5 ; 95 \% \mathrm{Cl}=2.5-21.4)$ and tight nuchal $(\mathrm{AOR}=3.1$; $95 \% \mathrm{Cl}=1.2-9.3)$.
\end{abstract}

Conclusion: Birth asphyxia is still prevalent in the study setting. The obtained findings indicated that the mothers aged $\geq 35$, being primigravida, preterm birth, meconium stained amniotic fluid and tight nuchal were the factors associated with birth asphyxia. The results of this study show the need for better maternal care, creating awareness about contributing factors of birth asphyxia to the maternity health professionals, careful monitoring of labor, and identifying and taking proper measures that could help in reducing the occurrence of birth asphyxia.

Keywords: Birth asphyxia, Prevalence, Contributing factors

\footnotetext{
* Correspondence: ritbano2244@gmail.com

Department of Midwifery, College of Medicine and Health Sciences,

Wachemo University, Hossana, Ethiopia
}

(c) The Author(s). 2019 Open Access This article is distributed under the terms of the Creative Commons Attribution 4.0 International License (http://creativecommons.org/licenses/by/4.0/), which permits unrestricted use, distribution, and reproduction in any medium, provided you give appropriate credit to the original author(s) and the source, provide a link to the Creative Commons license, and indicate if changes were made. The Creative Commons Public Domain Dedication waiver (http://creativecommons.org/publicdomain/zero/1.0/) applies to the data made available in this article, unless otherwise stated. 


\section{Background}

Birth asphyxia is defined by the World Health Organisation (WHO) as 'the failure to initiate and sustain breathing at birth' [1]. It is a major contributor to neonatal mortality worldwide [2-5], causing 24\% of all neonatal deaths [3] and $11 \%$ of deaths of children under 5 years of age [2]. Almost all asphyxia related deaths (98\%) occur during the first week of life [6]. About $75 \%$ of such deaths occur on the first day, and less than $2 \%$ after $72 \mathrm{~h}$ of birth [5].

Birth asphyxia is a leading cause of brain damage. If severe, it can injure brain cells and cause potentially fatal conditions, including hypoxic-ischemic encephalopathy, brain injuries, autism, attention deficit hyperactivity disorder, seizures, and cerebral palsy [7]. Survivors often face lifelong health problems (80\%), such as disabilities, developmental delays, palsy, intellectual disabilities, and behavioural problems [7-10]. Furthermore, birth asphyxia places financial and emotional burdens on the families and communities involved $[10,11]$.

Birth asphyxia is associated with a complex range of risk factors, which vary from industrialised and nonindustrialised countries. These factors are grouped according to whether they are before birth (antepartum risk actors), during birth (intrapartum risk factors), or after birth (postpartum risk factors) [12]. Antepartum risk factors include severe maternal hypotension or hypertensive diseases during pregnancy $[13,14]$, antepartum haemorrhage $[15,16]$, history of stillbirth [17], fewer than four antenatal care visits [14, 15, 17], oligohydramnios [14], maternal fever $[13,15,18]$, and maternal anaemia $[13,14$, $17]$, young maternal age [13, 18, 19], advanced maternal age [20], and low educational status (illiterate and primary education level) $[17,19]$. Intrapartum risk factors include malpresentation [13-15, 17, 21], prolonged second stage of labour $[15,16,22]$, home delivery $[13,18]$, obstructed labour [13, 18, 23], oxytocin use [16], and meconium stained amniotic fluid $[13-15,18]$. Fetal risk factors associated with birth asphyxia include low birth weight [15, 18], high birth weight [22], multiple gestation [14], tight nuchal cord [15, 22], preterm delivery [13, 14, 22], resuscitation, and fetal distress $[17,24]$.

The Federal Ministry of Health developed the first comprehensive National Child Survival Strategy (2015-2020) in 2015, aiming to reduce under-five mortality by two thirds. Since its development in 2015, several evidencebased interventions that need to be incorporated in the strategy have been initiated. These include community management of pneumonia through integrated community case management, community-based newborn sepsis management through community-based newborn care, newborn intensive care units, newborn corners, and the introduction of Haemophilus influenza, pneumococcal, and shifting PMTCT to 'Option B+' [25]. The guidelines to treat birth asphyxia are also well established in Ethiopia and made available even at the health-centre level for assessing and classifying [26].

Despite this, a high number of newborn deaths due to birth asphyxia were reported in Ethiopia. From observations thus far, the issue of birth asphyxia remains unresolved. Ethiopia's rate of neonatal mortality is still among the highest in sub-Saharan Africa [27, 28]. In 2015, nearly 240 babies in their first month died each day [29]. Birth asphyxia is the leading cause of neonatal deaths and accounts for about $31.6 \%$ of neonatal mortality, followed by preterm birth (21.8\%) and sepsis (18.5\%) [30]. Moreover, the findings from studies conducted in Tigray [31] and Gondor [32] to identify causes of neonatal mortality revealed that birth asphyxia was responsible for 35 and $12.5 \%$ of neonatal deaths respectively.

Analysis of birth asphyxia is important because it may reveal possible factors. Therefore, this study aims to assess the prevalence and contributing factors of birth asphyxia among neonates delivered in the Nigist Eleni Mohammed Memorial Teaching Hospital, Southern Ethiopia.

\section{Methods}

Study setting, population, sample seize and technique

This hospital-based cross-sectional study was undertaken at Nigist Eleni Mohammed Memorial Teaching Hospital in the Hossana Town, during June 1-30 in 2019. The single population proportion formula was used to determine the sample size with the following assumptions; the proportion of birth asphyxia was taken from the study conducted as Jimma Public Hospitals (12.5\%) [15], with a 95\% confidence interval (CI), margin error of 4 , and $5 \%$ non- response rate. Finally, the sample size was obtained at 279 for the present study using the systematic sampling technique. Every third woman from the delivery registration book, who delivered $\geq 28$ weeks with a live infant, was selected as a study subject. If a mother gave birth to more than one baby, one of these babies was selected using a simple random sampling method.

\section{Data collection procedure}

Data were collected using a combination of a pretested structured interviewer-administered questionnaire, observation check list and client's chart reviewed, which was used to retrieve medical information and mother's test results that could not be captured by the interview. The questionnaire was developed based on the instrument that was applied in other related studies [15-22, $31,32]$. It was structured into four parts, namely, sociodemographic characteristics, antepartum factors, intrapartum factors and fetal condition and postpartum factors. Three BSc. degree midwives who are able to speak both Hadiyisa (local language) and Amharic were 
recruited for the data collection, and three MSc. midwives participated in supervising the data collectors. Data collection began from the admission of a mother to the labour ward and lasted till the 5th minute after delivery. Data were collected throughout the day (including night). Data collectors followed the maternal conditions, labour progress and fetal conditions during follow up. The fetal heart rate was monitored through fetoschope and recorded every $30 \mathrm{~min}$ in the first stage of labour and every $5 \mathrm{~min}$ in the second stage of labour to identify fetal distress.

To ensure the quality of data to be gathered from the study subjects, the questionnaire was translated first to the local language and then translated back to English by experts to check its consistency. The instruments were pretested on $5 \%$ of the sample size in similar settings, and necessary modifications were made based on the nature of gaps identified in the questionnaire. Additionally, data collectors and supervisors were trained for a day by the investigators on the content of the questionnaire and the ways to collect the data. Moreover, the supervisors and the investigators closely followed the day-to-day data collection process during the pretest and the actual data collection. Furthermore, the filled questionnaire was collected and signed by the supervisor after it was checked for any missing items and completeness. Moreover, cross check was done on $10 \%$ of the sample size.

\section{Measurement \\ Birth asphyxia}

Birth asphyxia was considered when the Apgar score was $<7$ at the 5 th minutes. The trained data collectors (midwives) in the maternity ward and operating theatres performed the scoring and the information was documented on an Apgar score card.

\section{Prolonged second stage labor}

Prolonged if it exceeds $3 \mathrm{~h}$ with provision of regional anaesthesia, or $2 \mathrm{~h}$ in the absence of regional anaesthesia for nulliparas. It is multiparous if it exceeds $2 \mathrm{~h}$ with regional anaesthesia or $1 \mathrm{~h}$ without it. We have assessed this in numbers. Finally, the labor is classified as prolonged or not prolonged based on the definition.

\section{Nuchal cord}

Nuchal cord was defined as a loop of umbilical cord $\geq$ 360 degree around the fetal neck. At the time of delivery, each birth was recorded as having a tight nuchal cord, or no tight nuchal cord. 'Tight nuchal cord' was defined as the inability to manually reduce the loop over the fetal head.

\section{Data processing and analysis}

The data were entered into EpiData software (version 3.1) and analyzed using SPPS software (version 24.0). Descriptive statistics, frequency, and proportions were computed to summarize the data. Logistic regression analyses were conducted to identify contributing factors to birth asphyxia. Initially, bivariate logistic regression analysis was performed on all independent variables. Multivariable logistic regression was then performed on variables that had a $p$-value $\leq 0.25$ in the bivariate logistic regression analysis. The degree of association between independent, and dependent variables were assessed using odds ratio with 95\% confidence interval.

\section{Results}

\section{Socio-demographic characteristics}

A total of 279 participants were involved in this study, wherein the response rate was $100 \%$. Approximately, $83.9 \%$ of the participating mothers were aged 25-34 years. The majority of the participants were married 271 (97.1\%), 224 (80.3\%) of them were Hadiya ethnics, 209 (74.9\%) were protestants in terms of their religion, and 185 (66.3\%) were housewives. Regarding their educational status, 54 (19.4\%) of them had pursued higher education, and 122 (43.7\%) were rural residents (Table 1).

\section{Obstetrics, medical, and fetal characteristics}

Among the 279 study participants, 189 (67.7\%) of them were multigravida and another 90 (32\%) were primigravida. Twenty four (12.5\%) participants had ever experienced abortion, while 23 (12.4\%) of them had a history of still birth. The majority of the mothers, i.e. 252 (90.3\%) participants, were at the gestational age of $\geq 37$ weeks, while 157 (56.3\%) had $\geq$ four antenatal care visits. Furthermore, 44 (15.8\%) had faced pregnancy-related complications, wherein 13 (29.5\%), 12 (27.3\%), 11 (15\%), 5 (11.4\%), and $3(6.8 \%)$ encountered antepartum hemorrhage, hypertensive disorders, premature rupture of fetal membranes, hyperemesis gravidarum, and other, respectively. In this study, the overall prevalence rate of birth asphyxia was found to be $42(15.1 \%)$. Other obstetrics, medical and fetal characteristics are shown in Table 2 .

\section{Contributing factors of birth asphyxia}

The outcome of the bivariate logistic regression analysis showed that, mothers aged $\geq 35$, primigravida, pregnancy related complication, primigravida, prolonged labour, preterm birth, meconium stained amniotic fluid and tight nuchal cord were contributing factors of birth asphyxia. However, in multivariable logistic regression analysis, mothers aged $\geq 35$, primigravida, prolonged second stage of labor, preterm birth, meconium stained 
Table 1 Sociodemographic characteristics of mothers in the Nigist Eleni Mohammed Memorial Teaching Hospital, Southern Ethiopia, 2019

\begin{tabular}{|c|c|c|c|}
\hline Variable & & $\begin{array}{l}\text { Frequency } \\
(N=279)\end{array}$ & Percent \\
\hline \multirow[t]{3}{*}{ Age group } & $15-19$ & 17 & 6.1 \\
\hline & $20-34$ & 234 & 83.9 \\
\hline & $\geq 35$ & 28 & 10.0 \\
\hline \multirow[t]{2}{*}{ Residence } & Urban & 157 & 56.3 \\
\hline & Rural & 122 & 43.7 \\
\hline \multirow[t]{2}{*}{ Marital status } & Married & 271 & 97.1 \\
\hline & Other & 8 & 2.9 \\
\hline \multirow[t]{4}{*}{ Religion } & Protestant & 209 & 74.9 \\
\hline & Orthodox & 34 & 12.2 \\
\hline & Muslim & 30 & 10.8 \\
\hline & Catholic & 6 & 2.2 \\
\hline \multirow[t]{4}{*}{ Ethnicity } & Hadiya & 224 & 80.3 \\
\hline & Kambata & 28 & 10.0 \\
\hline & Silte & 18 & 6.5 \\
\hline & other (specify) & 9 & 3.2 \\
\hline \multirow[t]{4}{*}{ Educational status } & Able to read and write & 29 & 10.4 \\
\hline & Primary school completed & 101 & 36.2 \\
\hline & High and preparatory school & 95 & 34.1 \\
\hline & Higher institution & 54 & 19.4 \\
\hline \multirow[t]{4}{*}{ Occupation } & Government employee & 41 & 14.7 \\
\hline & Merchant & 43 & 15.4 \\
\hline & Housewife & 185 & 66.3 \\
\hline & Others $^{a}$ & 10 & 3.6 \\
\hline
\end{tabular}

aprivate, student

amniotic fluid and tight nuchal cord were contributing factors of birth asphyxia. Mothers aged $\geq 35$ were more or six times more likely to have experienced birth asphyxia respect to women in the age group between 20 and 34 years old $(\mathrm{AOR}=6.4 ; 95 \% \mathrm{CI}=2.0-20.5)$. Similarly, the prolonged second stage of labor was 4.6 times more likely to have a birth asphyxia than their counterparts (AOR $=4.6 ; 95 \% \mathrm{CI}=1.6-13.3$ ). Additionally, birth asphyxia was five times more likely to occur in primigravida in comparison to their counterparts $(\mathrm{AOR}=5.1$; 95\% CI $=2.0-13.3$ ). Furthermore, preterm birth was nearly 5 times more likely to develop birth asphyxia respect to their counterpart $(\mathrm{AOR}=4.7 ; 95 \% \mathrm{CI}=1.5$ 14.1). Moreover, meconium stained amniotic fluid were 7.5 times more likely faced births asphyxia than their counterparts $(\mathrm{AOR}=7.5 ; 95 \% \mathrm{CI}=2.5-21.4)$. Furthermore, tight nuchal cord were more or 3 times more likely to develop birth asphyxia respect to their counterpart $(\mathrm{AOR}=3.1 ; 95 \% \mathrm{CI}=1.2-9.3)$ (Table 3$)$.
Table 2 Obstetrics, medical, and fetal characteristics in the Nigist Eleni Mohammed Memorial Teaching Hospital, Southern Ethiopia, 2019

\begin{tabular}{|c|c|c|c|}
\hline Variables & & Frequency & Percent \\
\hline \multirow{2}{*}{$\begin{array}{l}\text { Stage of labor at admission } \\
(n=271)\end{array}$} & First stage & 260 & 96.0 \\
\hline & Second stage & 11 & 4.0 \\
\hline \multirow[t]{3}{*}{ Status of labor $(n=279)$} & Spontaneous & 254 & 91.0 \\
\hline & Induction & 17 & 6.1 \\
\hline & Elective CS & 8 & 2.9 \\
\hline \multirow[t]{3}{*}{ Mode of current delivery } & Normal vaginal & 224 & 80.3 \\
\hline & Caesarian section & 40 & 14.3 \\
\hline & Operative vaginal & 15 & 5.4 \\
\hline \multirow[t]{2}{*}{ Augmentation $(n=254)$} & NO & 232 & 91.3 \\
\hline & Yes & 22 & 8.6 \\
\hline \multirow{2}{*}{$\begin{array}{l}\text { Prolonged second stage } \\
\text { of labor }(n=271)\end{array}$} & No & 245 & 90.4 \\
\hline & Yes & 26 & 9.6 \\
\hline \multirow{2}{*}{$\begin{array}{l}\text { Malpresentation/ } \\
\text { malpresentation }(n=271)\end{array}$} & No & 258 & 95.2 \\
\hline & Yes & 13 & 4.8 \\
\hline \multirow[t]{2}{*}{ Obstructed labor $(n=271)$} & No & 252 & 93 \\
\hline & Yes & 19 & 7 \\
\hline \multirow[t]{2}{*}{ Sex of newborns $(n=279)$} & Female & 130 & 46.6 \\
\hline & Male & 149 & 53.4 \\
\hline \multirow[t]{3}{*}{$\begin{array}{l}\text { Birth weight of newborn } \\
\text { babies }(n=279)\end{array}$} & $\begin{array}{l}\text { Low birth weight } \\
(<2500 \mathrm{~g})\end{array}$ & 34 & 12.2 \\
\hline & $\begin{array}{l}\text { Normal birth weight } \\
(2500-4000 \mathrm{~g})\end{array}$ & 224 & 80.3 \\
\hline & $\begin{array}{l}\text { Macrosomia } \\
(>4000 \mathrm{~g})\end{array}$ & 21 & 7.5 \\
\hline \multirow{2}{*}{$\begin{array}{l}\text { Number of delivery/fetuses } \\
(n=279)\end{array}$} & Single fetus & 270 & 96.8 \\
\hline & Twin & 9 & 3.2 \\
\hline \multirow[t]{2}{*}{ Resuscitation ( $n=279)$} & No & 247 & 88.5 \\
\hline & Yes & 32 & 11.5 \\
\hline \multirow[t]{3}{*}{ Fetal Presentation $(n=279)$} & Vertex presentation & 264 & 94.6 \\
\hline & Breech & 9 & 3.2 \\
\hline & Others & 6 & 2.2 \\
\hline \multirow{2}{*}{$\begin{array}{l}\text { Tight nuchal cord } \\
(n=279)=\end{array}$} & No & 250 & 89.6 \\
\hline & Yes & 29 & 10.4 \\
\hline \multirow{2}{*}{$\begin{array}{l}\text { Meconium stained amniotic } \\
\text { fluid }(n=279)\end{array}$} & Yes & 27 & 9.7 \\
\hline & No & 252 & 90.3 \\
\hline \multirow{2}{*}{$\begin{array}{l}\text { Chronic medical illness } \\
(n=279)\end{array}$} & No & 268 & 96.1 \\
\hline & Yes & 11 & 3.9 \\
\hline \multirow{2}{*}{$\begin{array}{l}\text { Acute febrile illness during } \\
\text { pregnancy }(n=279)\end{array}$} & No & 227 & 81.4 \\
\hline & Yes & 52 & 18.6 \\
\hline \multirow{2}{*}{$\begin{array}{l}\text { Hemoglobin Level } \\
\text { (intrapartum) }(n=261)\end{array}$} & $\geq 11 \mathrm{~g} / \mathrm{dl}$ & 219 & 78.5 \\
\hline & $<11 \mathrm{~g} / \mathrm{dl}$ & 42 & 15.1 \\
\hline
\end{tabular}


Table 3 Contributing factors of birth asphyxia at the Negest Eleni Mohammed Memorial Teaching Hospital, Southern Ethiopia, 2019

\begin{tabular}{|c|c|c|c|c|c|}
\hline \multirow[t]{2}{*}{ Variables } & & \multicolumn{2}{|c|}{ Birth asphyxia } & \multirow[t]{2}{*}{ COR $(95 \% \mathrm{Cl})$} & \multirow[t]{2}{*}{ AOR $(95 \% \mathrm{Cl})$} \\
\hline & & No & Yes & & \\
\hline \multirow[t]{3}{*}{ Age group } & $<20$ & 14 & 3 & $1.5(.4,5.4)^{*}$ & $.6(.1,2.5)$ \\
\hline & 20-34 (ref.) & 204 & 30 & 1 & 1 \\
\hline & $\geq 35$ & 19 & 9 & $3.2(1.3,7.8)^{*}$ & $6.4(2.0,20.5)^{* *}$ \\
\hline \multirow[t]{2}{*}{ Residence } & Urban (ref.) & 137 & 20 & 1 & 1 \\
\hline & Rural & 100 & 22 & $1.5(.8,2.9)^{*}$ & $.9(.4,2.1)$ \\
\hline \multirow[t]{2}{*}{ Gravidity } & Primigravida & 71 & 19 & $1.9(1.0,3.8)^{*}$ & $5.1(2.0,13.3)^{* *}$ \\
\hline & Multigravida (ref.) & 166 & 23 & 1 & 1 \\
\hline \multirow[t]{2}{*}{ Pregnancy related complications } & No (ref.) & 205 & 30 & 1 & 1 \\
\hline & Yes & 32 & 12 & $2.6(1.2 .5 .5)^{*}$ & $2.0(.7,5.9)$ \\
\hline \multirow[t]{2}{*}{ Prolonged second stage of labour } & No (ref.) & 216 & 29 & 1 & 1 \\
\hline & Yes & 16 & 10 & $4.7(2.0,11.2)^{*}$ & $4.6(1.6,13.3)^{* *}$ \\
\hline \multirow[t]{2}{*}{ Gestational age } & $\geq 37$ weeks (ref.) & 219 & 33 & 1 & 1 \\
\hline & $<37$ weeks & 18 & 9 & $3.3(1.4,8.0)^{*}$ & $4.7(1.5,14.1)^{* *}$ \\
\hline \multirow[t]{2}{*}{ Color of amniotic fluid } & Clear (ref.) & 222 & 30 & 1 & 1 \\
\hline & Meconium stained & 15 & 12 & $5.9(2.5,13.8)^{*}$ & $7.5(2.5,21.4)^{* * *}$ \\
\hline \multirow[t]{2}{*}{ Tight nuchal cord } & No (ref.) & 218 & 32 & 1 & 1 \\
\hline & Yes & 19 & 10 & $3.6(1.5,8.4)^{*}$ & $3.1(1.2,9.3)^{* *}$ \\
\hline
\end{tabular}

\section{Discussion}

In this study, the overall prevalence of birth asphyxia was found to be $15.1 \%$. This is higher than seen in studies conducted in Jimma, Dire Dawa, and Tanzania which were $12.5,3.6$, and $11.5 \%$, respectively $[15,33,34]$. The increased prevalence may be due to the hospitals from the study being referral hospitals, which had inferior health facilities. Further, this difference could be an indicator of the ineffectiveness of national strategies for maternal and newborn care services. In contrast, this study found a lower prevalence of birth asphyxia as compared to studies carried out in Zambia and Nigeria which were 23 and $24.7 \%$, respectively $[8,35]$. The variation in our study might be due to differences in study design, setting, sample size and accessible maternal health care services.

In this study, mothers aged $\geq 35$ were one of the contributing factors to birth asphyxia rates. The following discovery was very nearly found to be a universal fact: the increased age of the mother increased the risk of several adverse outcomes [24, 36, 37]. Similar findings were also reported from a study carried out in Cameroon [20] which revealed that mothers aged $\geq 35$ were more likely to experience a birth asphyxia. However, in contrast to what was found in Ethiopia [19], and Pakistan [13, 22], a younger maternal age was not found to be a contributing factor of birth asphyxia in this study.

Primigravida was found to be a contributing factor of birth asphyxia and this was consistent with the research conducted in India [14], Ethiopia [15], and Pakistan [18, $22]$. The most common obstetric complication was failure to progress in labor [21], which may subsequently result in the delivery of an asphyxiated baby.

This study also showed that mothers encountering a prolonged second stage of labor were at a greater risk for birth asphyxia with respect to their counterparts. These findings were similar to those of studies conducted in Ethiopia, Colombia and Pakistan [15, 16, 22]. One reason that babies born after a prolonged labor have a greater risk of birth asphyxia may be due to umbilical cord problems or the stress of too many contractions.

Meconium stained amniotic fluid was a contributing factor to birth asphyxia, similar to what was reported in Ethiopia [15], India [17], and Pakistan [18]. Possibly, the presence of meconium in the amniotic fluid may cause aspiration of meconium-stained amniotic fluid to occur, and this can block small airways, deactivate surfactants and may also inhibit surfactant synthesis, resulting in birth asphyxia $[38,39]$. As shown by the present study, prematurity was found to have a significant association with birth asphyxia, which is in line with what has been found in Ethiopia [15] and Pakistan [18, 22]. A baby being born before 37 completed weeks of pregnancy may develop birth asphyxia due to an insufficient amount of surfactant in the lungs. Surfactant creates a continuously reforming surface layer over the alveoli which reduces surface tension, prevents atelectasis and maintains alveolar stability. A 
deficiency in pulmonary surfactant production causes Respiratory Distress Syndrome [40, 41].

Birth asphyxia was also found to be associated with a tight nuchal cord. This finding is similar to that of the studies conducted in Ethiopia [15] and Pakistan [22]. This might be related to tight nuchal cord cords can interrupt normal blood, nutrient, and oxygen exchange by compressing the umbilical cord, or restricts arteries and veins in the fetal neck, this can lead to birth asphyxia $[42,43]$.

\section{Limitations of the study}

In this study, the Apgar score was used to diagnose asphyxia. However, using the Apgar score alone to diagnose birth asphyxia has been found to be inappropriate as it is an expression of the infant's physiological condition at one point in time, which includes subjective components. Also, the study relied on hospital deliveries. However, several deliveries occurred outside the hospital, making it difficult to capture data such as birth asphyxia, so the estimates contained in this study may have underreported the cases at the community level. Additionally, sometimes women who came to the hospital may encounter labor complications, compared to women that deliver out of hospital. Therefore, this may also cause overestimation of the prevalence of birth asphyxia.

\section{Conclusion}

Birth asphyxia is still prevalent in the study setting. Primigravida, prolonged labour, preterm birth, and mothers aged $\geq 35$ meconium stained amniotic fluid and tight nuchal cord were contributing factors of birth asphyxia. Results of this study show the need for the better maternal care, creating awareness about contributing factors of birth asphyxia to the maternity health professionals, careful monitoring of labor, identifying and taking proper measure could help in decreasing the occurrence of birth asphyxia. The results of the study will help policy-makers, program designers and Nongovernmental organizations to support the study area. Additionally, the findings of the study can also help as a secondary data for further study in same area of inquiry.

\section{Abbreviations}

AOR: Adjusted odd ratio; Cl: Confidence interval; COR: crude odds ratio; FMOH: Federal ministry of health; PMTCT: Prevention of mother-to-child transmission of HIV; SPSS: statistical package for social sciences; WHO: World Health Organisation

\section{Acknowledgements}

The authors extend their gratitude to Wachemo University, Hospital authorities, supervisors, data collectors, and respondents who participated on this study.

\section{Authors' contributions}

RA conceptualized the idea, carried out the analysis, interpreted the result, participated the drafting the manuscript, revised the manuscript, and approved the final manuscript for submission, responsible for submission and communication about the manuscript. BA, NG reviewed the manuscript and approved the final manuscript for submission. AA conceptualized the idea, reviewed the manuscript, and approved the final manuscript for submission. HM the conceptualization, data analyses, revised and approved for the final manuscript for submission.

\section{Funding}

Wachemo University funded the research and it is open for the researchers to publish the manuscript. The funders had no role in study design, data collection and analysis, decision to publish, or preparation of the manuscript.

Availability of data and materials

The datasets used and /or analysed during the current study are available from the corresponding author on reasonable request.

\section{Competing interest}

The authors declare that there is no conflict of interest.

\section{Ethics approval and consent to participate}

The ethical clearance letter was obtained from the Wachemo University, research and review committee. Additionally, permission was obtained from the hospital authority before commencing the data collection. Finally, written consent informed was requested from each participant (mother), which has been included in the study during the data collection time, after explaining the objectives of the study to them. Parental consent was taken for respondents who were under 18 years of age. The participants were informed about the purpose, procedures, potential risks, and benefits of the study. Furthermore, the participants were ensured that refusal to consent or withdrawal from the study would not alter or put at risk their access to care.

\section{Consent for publication}

Not applicable.

Received: 10 September 2019 Accepted: 23 December 2019

Published online: 30 December 2019

References

1. Maternal and Newborn Health/Safe Motherhood Unit. Division of Reproductive Health (Technical Support). Basic Newborn Resuscitation: A Practical Guide, vol. 4. Geneva: World Health Organization; 1997. Accessed at https://www.who.int/maternal_child_adolescent/documents/who_rht_ msm_981/en/pdf

2. Md SO. Global burden of neonatal disease: caring for the world's most vulnerable patients 2017 newborn pediatric critical care conference; 2017.

3. WHO. Maternal and Child Epidemiology Estimation Group (MCEE). Estimates for child causes of death 2000-2016. 2018.

4. Lee C, Luke C., James M, Subarna K, Steven C., Ramesh K, et al. Risk factors for neonatal mortality due to birth asphyxia in Southern Nepal: a prospective, Community-Based Cohort Study. Pediatrics. 2008, 121(5): e1381-e1390.

5. Velaphi S, Pattinson R. Avoidable factors and causes of neonatal deaths from perinatal asphyxia-hypoxia in South Africa: national perinatal survey. Ann Trop Paediatr. 2017;27(2):99-106.

6. Sankar MJ, Natarajan CK, Das RR, Agarwal R, Chandrasekaran A, Paul VK. When do newborns die? A systematic review of timing of overall and cause-specific neonatal deaths in developing countries. J Perinatol. 2016;36:S1-S11.

7. Peeva V, Golubnitschaja O. Birth asphyxia as the most frequent perinatal complication. In: Golubnitschaja O, editor. Predictive diagnostics and personalized treatment: dream or reality? NewYork: Nova Science Publishers; 2009. p. 499-50.

8. Halloran R, McClure E, Chakraborty H, Chomba E, Wright LL, Carlo WA. Birth asphyxia survivors in a developing country. J Perinatol. 2009;29:243-9.

9. Ahearne CE, Boylan GB, Murray DM. Short and long term prognosis in perinatal asphyxia: an update. World J ClinPediatr. 2016;5(1):67-74.

10. Eunson P. The long-term health, social, and financial burden of hypoxicischemic encephalopathy. Dev Med Child Neurol. 2015;57(3):48-50.

11. Enweronu-Laryea CC, Andoh HD, Frimpong-Barfi A, Asenso-Boadi FM. Parental costs for in-patient neonatal services for perinatal asphyxia and low birth weight in Ghana. PLoS One. 2018;13(10):e0204410. 
12. Roberto A, Annalisa P, Maria DP. Perinatal asphyxia in the term newborn. J Pediatr Neonatal Individualized Med. 2014;3(2):e030269.

13. Aslam HM, Saleem S, Afzal R, lqba U, Saleem SM, Abid MW, et al. Risk factors of birth asphyxia. Ital J Pediatr. 2014. https://doi.org/10.1186/s13052-014-0094-2.

14. Yadav N, Damke S. Study of risk factors in children with birth asphyxia. Int J Contemp Pediatr. 2017:4(2):518-26.

15. Wayessa JZ, Belachew T, Joseph J. Birth asphyxia and associated factors among newborns delivered in Jimma zone public hospitals, Southwest Ethiopia: a cross-sectional study. J Midwifery and Reprod Health. 2018;6(2):1289-95.

16. Torres-Muñoz J, Rojas C, Mendoza-Urbana D. Risk factors associated with the development of perinatal asphyxia in neonates at the Hospital Universitario de Valle, Cali, Colombia, 2010-2011. Biomedical. 2017;37(1):51.6.

17. Bahubali G, Vishnu BB, Rao R, Nandakumar S, Adhisivam B, Rojo J, et al. Antenatal and intrapartum risk factors for perinatal asphyxia: A case control study. Curr Pediatr Res. 2013;17(2):119-22.

18. Solayman M, Hoque S, Akber T, Islam MI, Islam MA. Prevalence of Perinatal Asphyxia with Evaluation of Associated Risk Factors in a Rural Tertiary Level Hospital. KYAMC J. 2017;8:1

19. Ibrahim NA, Muhye A, Abdulie S. Prevalence of birth asphyxia and associated factors among neonates delivered in Dilchora referral hospital, in Dire Dawa, Eastern Ethiopia. Clin Mother Child Health. 2017;14:4. https://doi. org/10.4172/2090-7214.1000.

20. Ngowa JD, Ngassam A-N, Dohbit JS, Nzedjom C, Kasia JM. Pregnancy outcome at advanced maternal age in a group of African women in two teaching Hospitals in Yaounde, Cameroon. Pan African Med J. 2013;14:134. https://doi.org/10.11604/pamj.2013.14.134.231

21. Onoja B, Onoja KO, Ekwempu C. Obstetric performance of elderly primigravida in Jos University Teaching Hospital Jos Nigeria. J Med. 2012;9:1.

22. Tabassum F, Rizvi A, Ariff S, Soofi S, Zulfiqar AB. Risk factors associated with birth asphyxia in Rural District Matiari, Pakistan: a case control study. Int J Clin Med. 2014;5:1430-41.

23. West BA, Opara PI. Perinatal asphyxia in a specialist hospital in Port Harcourt, Nigeria. Niger J Paed. 2013;40(3):206-10.

24. Laopaiboon M, Lumbiganon P, Intarut N, Mori R, Ganchimeg T, Vogel JP, Souza JP, Gulmezoglu AM. On behalf of the WHO multicountry survey on maternal newborn Health Research network. Advanced maternal age and pregnancy outcomes: a multicountry assessment. BJOG. 2014;121(1):49-56

25. Federal Democratic Republic of Ethiopia Ministry of Health. National Strategy for Newborn and Child Survival in Ethiopia, 2015/16 - 2019/20 Maternal and Child Health Directorate Federal Ministry of Health. Addis Ababa; 2015

26. WHO, UNICEF, Amref. Integrated Management of Newborn and Childhood Illness. Federal Democratic Republic of Ethiopia Ministry of Health. Addis Ababa; 2016.

27. World Health Organization. Regional Office for Africa. WHO Country Cooperation Strategy 2012-2015. Ethiopia: World Health Organization. Regional Office for Africa; 2013. Accessed at : http://apps.who.int/iris/ bitstream/10665/136003/3/ccs_ethiopia.pdf

28. World Health Organization UNICEF. Every Newborn: an action plan to end preventable deaths. Geneva: World Health Organization; 2014. Accessed at: https://www.who.int.documents.every-newborn-action.pdf

29. United Nations, Department of Economic and Social Affairs, Population Division. World Population Prospects: The 2015 Revision. Accessed at: https://www.un.org/en/development/desa/publications/world-populationprospects-2015.revision.html.

30. WHO. MCEE-WHO methods and data sources for child causes of death 2000-2015 (Global Health Estimates Technical Paper WHO/HIS/HSI/GHE/ 2016.1). Geneva: Department of Information, Evidence and Research WHO; 2016. Accessed at: https://www.who.int.Child.COD_method_2000_2015.pdf

31. Hayelom GM, Berhe WS. Cause of neonatal deaths in northern Ethiopia: a prospective cohort study. BMC Public Health. 2017;17:62.

32. Demise AG, Alemu F, Gizaw MA, Tigabu Z. Patterns of admission and factors associated with neonatal mortality among neonates admitted to the neonatal intensive care unit of University of Gondar Hospital. Northwest Ethiopia. 2017;8:57-64

33. Ibrahim NA, Muhye A, Abdulie S. Prevalence of birth asphyxia and associated factors among neonates delivered in Dilchora referral hospital, in Dire Dawa, Eastern Ethiopia. Clin Mother Child Health. 2017;14:279. https:// doi.org/10.4172/2090-7214.1000279.

34. Irene NS, Deborah NM, Kahindo K, Rune NP, Sia EM. Prevalence, severity and early outcomes of hypoxic ischemic encephalopathy among newborns at a tertiary hospital, in northern Tanzania. BMC Pediatr. 2017;17:131. https://doi. org/10.1186/s12887-017-0876-y.

35. Aliyu I, Lawal TO, Onankpa B. Prevalence and outcome of perinatal asphyxia: Ourexperience in a semi-urban setting. Trop J Med Res. 2017;20:161-5.

36. Almeida NK, Almeida RM, Pedreira CE. Adverse perinatal outcomes for advanced maternal age: a cross-sectional study of Brazilian births. J Pediatr. 2015;91(5):493-8.

37. Moses D, Holm BA, Spitale P, Liu M, Enhorning G. Inhibition of pulmonary surfactant function by meconium. Am J Obstet Gynecol. 1991;164(2):477-81.

38. Ochs M, Schüttler M, Stichtenoth G, Herting E. Morphological alterations of exogenous surfactant inhibited by meconium can be prevented by dextran. Respir Res. 2006;7:86

39. Herting E, Rauprich P, Stichtenoth G, Walter G, Johansson J, Robertson B. Resistance of different surfactant preparations to inactivation by meconium. Pediatr Res. 2001:50:44-9.

40. Polin RA, Carlo WA. Surfactant replacement therapy for preterm and term neonates with respiratory distress. Pediatrics. 2014;133:156.

41. Picker N, Kolecha S. Pathophysiology of Respiratory Distress syndrome. Pediatr Child Health. 2008:9:4

42. Peesay M. Nuchal cord and its implications. Peesay maternal health, neonatology, and. Perinatology. 2017;3:28. https://doi.org/10.1186/s40748017-0068-7.

43. Henry E, Andres RL, Christensen RD. Neonatal outcomes following a tight nuchal cord. J Perinatol. 2013:33:231-4.

\section{Publisher's Note}

Springer Nature remains neutral with regard to jurisdictional claims in published maps and institutional affiliations.
Ready to submit your research? Choose BMC and benefit from:

- fast, convenient online submission

- thorough peer review by experienced researchers in your field

- rapid publication on acceptance

- support for research data, including large and complex data types

- gold Open Access which fosters wider collaboration and increased citations

- maximum visibility for your research: over $100 \mathrm{M}$ website views per year

At $\mathrm{BMC}$, research is always in progress.

Learn more biomedcentral.com/submissions 